\title{
Inmotic design proposal articulated with the policies of the municipality of the City of Córdoba, Argentina
}

\section{SIGRADI2018 TECHNOPOLITICAS \\ xxii congresso da sociedade iberoamericana de gráfica digital 22th conference of the iberoamerican society of digital graphics 07|08|09|novembro|2018 iau usp | são carlos | sp br}

\author{
Silvia Patricia Hernandez \\ FAUD.UNC | Argentina| arqhernandezster@gmail.com \\ Cristina Chaves \\ FAUD.UNC | Argentina| cristinacha@hotmail.com \\ Lucía Ron \\ FAUD.UNC | Argentina| lucia-ron@hotmail.com \\ Mariángeles Genero \\ FAUD.UNC | Argentina|| mariangelagenero@gmail.com
}

\begin{abstract}
It was proposed to investigate and develop technological advances, considering the intensive presence of digital and hybrid technologies in everyday life. These technologies were used, including advances in design, applying them in useful design proposals for a specific urban space, called interstitial. The team developed a physical space for the dissemination of the twitter of the Municipal Culture Secretary of the City of Córdoba what democratizing the information so that it is available to everyone.
\end{abstract}

Keywords: Urban micro-architecture; Inmótics; Self-service information; City Government.

\section{INTRODUCCIÓN}

El diseño concreto que se presenta en esta propuesta es continuación y evolución de un trabajo de investigación realizado en el marco del programa aprobado por la Secretaría de Ciencia y Técnica de la Universidad Nacional de Córdoba "Acondicionamiento eficiente del hábitat construido. I+D+i (innovación) en confort, calidad ambiental y eficiencia energética de los espacios arquitectónicos y urbanos" (Dir. Dr. Arq Arturo Maristany).

En esta instancia presentamos los resultados del proceso de diseño, donde desarrollamos un legajo del proyecto con un equipo interdisciplinario formado por arquitectos, diseñadores industriales e ingenieros especialistas.

Según Perez de Lama (2017), la hipótesis tecnopolítica amplia consiste en afirmar que aspectos de gran relevancia de las relaciones de poder que caracterizan las sociedades contemporáneas se producen por medio de los sistemas tecnológicos, o más precisamente sociotécnicos. Coincidimos que las tecnologías, bajo una apariencia de efectividad en las maneras en que son implementadas socialmente, constituyen unas de las principales fuerzas que organizan la vida y la sociedad contemporáneas. (imagen1)

Millones de personas usan Twitter para conversar y difundir ideas breves (microblogging). Se encuentran desde noticias hasta difusión de marcas y empresas. Actualmente ya hay más de 320 millones de usuarios activos (mensuales) que publican un promedio de 500 millones de Tweets a diario. Un $22 \%$ de la gente en
Twitter tiene entre 16-24 años; los de edades entre 25-34 años son el mayor grupo, con un $29 \%$. A estos les siguen, con un $27 \%$, los usuarios entre $35-44$ años. Con un porcentaje más bajo cuentan las edades entre 45-54 con un $18 \%$ y el $5 \%$ restante es para los usuarios de 55 a 64 años (Twitter inc., 2018).

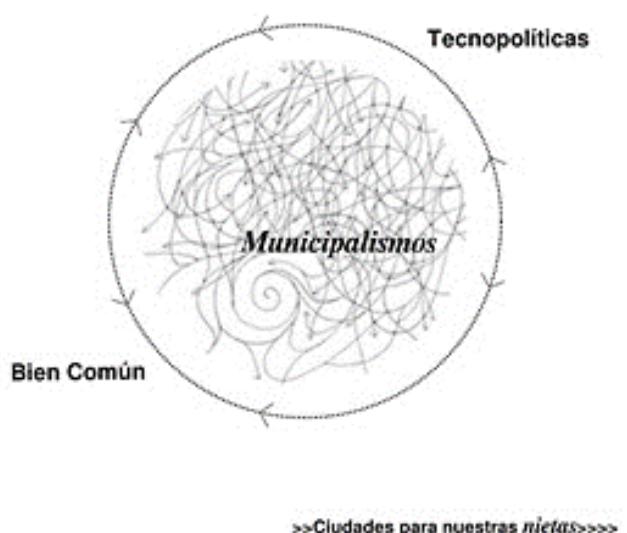

Imagen 1: Perez de Lama

Esta red social es una de las que tiene un crecimiento más lento; sin embargo se vuelve indispensable para la estrategia de social media marketing debido a varios aspectos:

- Su fortaleza en la información en tiempo real.

- Se puede convertir en el medio de comunicación oficial de una marca o empresa. 
- Es una red social mayoritariamente pública lo que permite que a las marcas realizar escucha social a través de ella.

Esta Secretaría organiza, gestiona y auspicia numerosos eventos diarios. La Secretaría de Cultura tiene una propuesta propia y además descentraliza su propuesta a través de la programación de distintas actividades en los barrios. La difusión de estos eventos se realiza principalmente por las redes sociales, en particular Twitter, a través de una cuenta oficial que utiliza el hashtag (etiqueta) \#qué tenemos hoy. (imagen2)

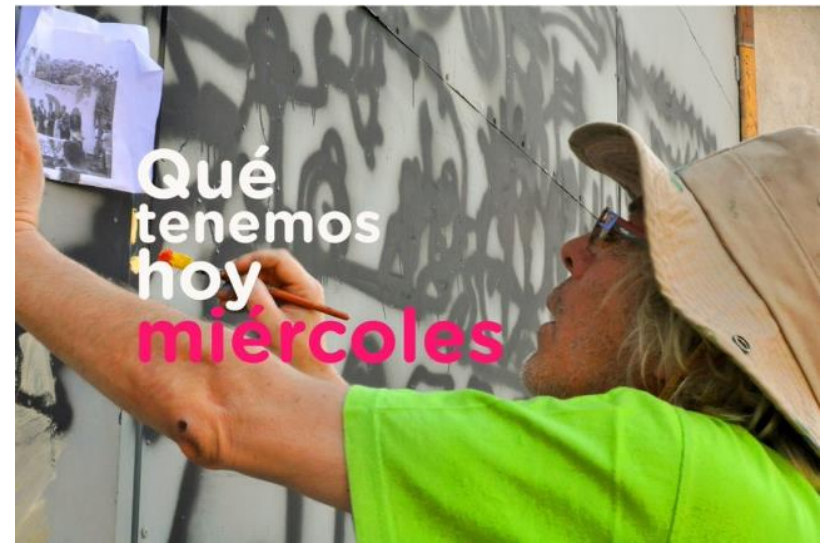

Imagen 2: hashtag del gobierno de la ciudad de Córdoba

Sin embargo, este sistema de difusión tiene varias falencias:

- Se difunden muchas actividades, pero la dinámica propia de la red social hace que los mensajes sean cada vez más difíciles de localizar o de recibir (pasan al limbo twittero).

- Muchos ciudadanos no tienen inclusive acceso al servicio de microblogging de Twitter, o no lo consultan con una frecuencia diaria.

- La cuenta oficial todavía no tiene consolidado un perfil específico para la difusión de eventos, y su llegada directa es a pocos usuarios (quizás ni siquiera el público al que están orientados algunos eventos).

Estos hilos de Twitter o tweetstorms, que se lanzaron en 2017, aportan continuidad, serialidad y contexto, frente a la fragmentación, dispersión y aleatoriedad del timeline. Su popularidad se debe a la saturación que produce el contenido snack y a la búsqueda, por parte de los usuarios, de una mayor profundidad argumental y narrativa sin salir de la plataforma.

Aprovechando esto, se busca consolidar el hashtag \#quetenemoshoy como marca, para que sea reconocido por una mayor cantidad de ciudadanos, convirtiéndose en un referente de eventos culturales públicos. Consideramos que Twitter no basta para el acceso e intercambio de información democrática. Convencidos de que poder acceder modifica los modos de hacer y las voluntades de los usuarios, este equipo propone dispositivos coincidiendo con Gutierrez-Rubí (2010) en que la tecnopolítica puede cambiar las ecuaciones, al permitir la participación activa de los ciudadanos.

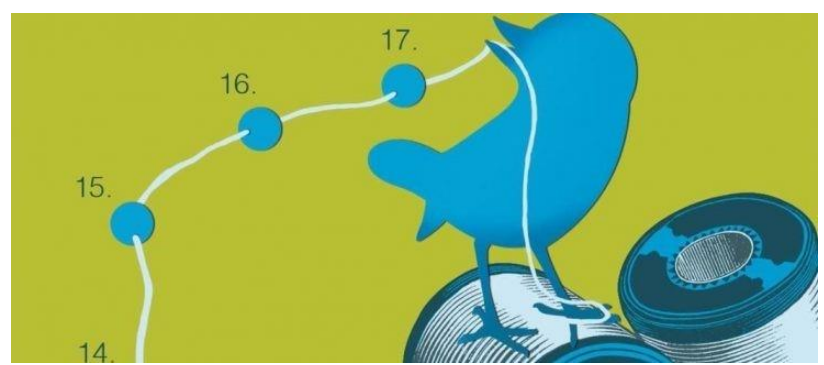

Imagen 3: El hilo de twitter, Gutierrez Rubi

Determinamos que cada instancia de un proceso de participación se sitúa dentro de un ámbito (territorial y/o sectorial) y se define por una serie de categorías y subcategorías (por ejemplo, temáticas) que afectan solo a dicho espacio virtual y/o real.

Tomamos al usuario como voces que son redes, proponiendo que los usuarios tengan actividad en nuestras tipologías y por qué no en nuestros diseños. Nos preocupa la aparente democratización de la información: coincidiendo con Loader y Mercea (2012), es aparente porque hay usuarios que no participan en las redes de información o no tienen un acceso en igualdad de condiciones. Por eso creamos esta tipología física, para la información manejada por twitter desde la Secretaría de Cultura del Gobierno de Córdoba. Este producto está respaldado por las encuestas a posibles usuarios y estudios en los sitios donde sería posible ubicarlo.

\section{PLANTEAMIENTO DEL PROYECTO}

La hipótesis planteada apunta a que es posible proponer alternativas a las propuestas de difusión de la secretaría de cultura del municipio, desde equipos interdisciplinarios de investigación, diseñando tipologías de microarquitectura urbana, para beneficio de la ciudad, transformándolas en diseño útil para determinados espacios urbanos llamados residuales o intersticiales, y generar espacios o reinterpretarlos para que sean interactivos, inclusivos y sustentables con tecnología domótica.

El objetivo general es realizar una propuesta de microarquitectura urbana inmótica, para la difusión de eventos llevados adelante por la secretaría de Cultura de la municipalidad de Córdoba, que responda a las preexistencias ambientales del sitio de implantación (un espacio urbano público interstitcial), sea autosustentable, inclusiva, y desarrollada con tecnología local. 


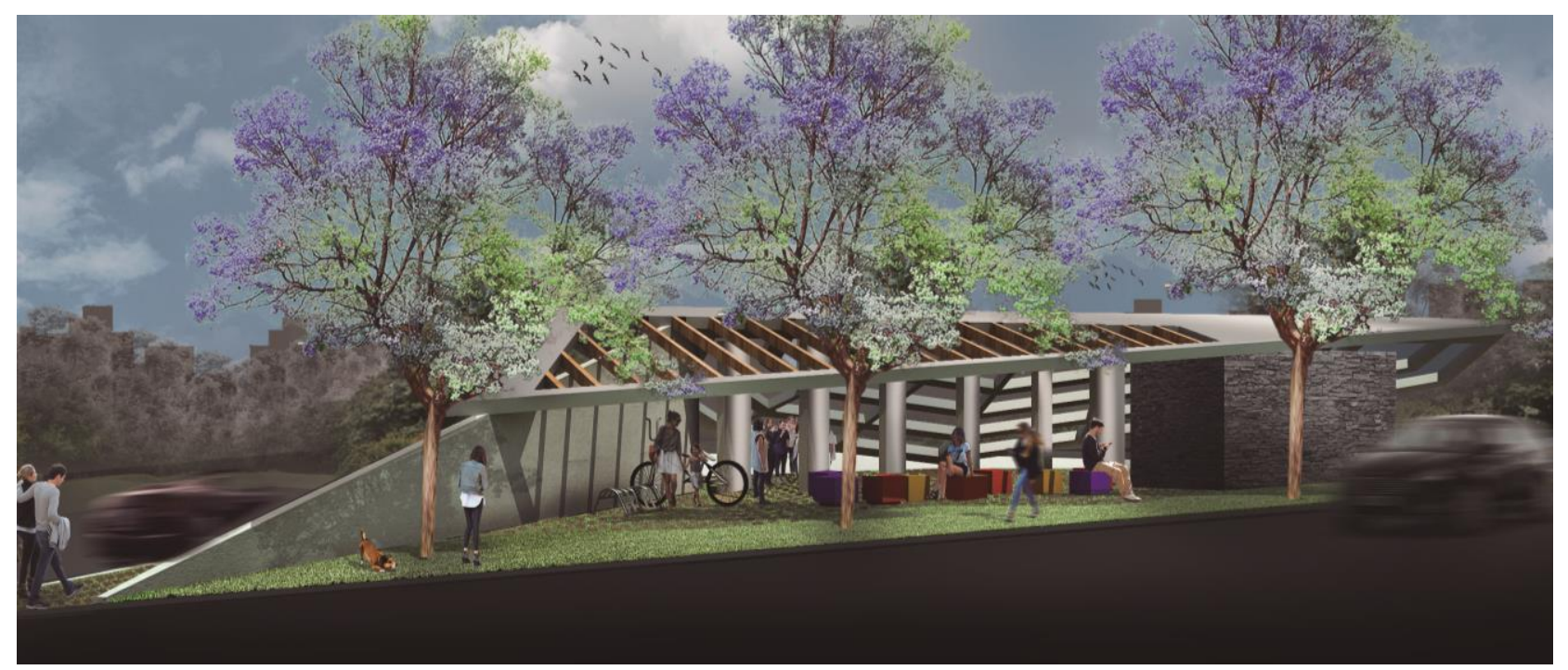

Imagen 4: vista propuesta, Imagen propia.

Entre los objetivos particulares, se propone

1. Analizar los requerimientos del programa solicitado, comparándolo con las necesidades concretas de los usuarios potenciales: para esto, estudiar los comportamientos de los usuarios, la interacción propuesta, las preferencias y rendimientos.

2. Definir una ubicación para el dispositivo, que sea un espacio público intersticial -hoy desocupadopero con la suficiente visibilidad y accesibilidad para lograr el objetivo principal.

3. Desarrollar un soporte físico que albergue actividades de información, compra/venta de tickets, trasmisión en directo de eventos.

4. Diseñar un espacio sustentable, que respete las preexistencias ambientales, considerando en este sitio determinado las condiciones urbanísticas y espaciales, climáticas, sonoras, flujos de personas y vehículos, existencia de redes de infraestructura, valor paisajístico y patrimonial, etc.

5. Trabajar con la inmótica alcanzando sus objetivos principales de confort, economía/eficiencia en su montaje y funcionamiento, y seguridad; favorecer el uso de elementos y tecnología ya disponible en nuestro medio, que pueda ser instalada y gestionada por especialistas locales.

6. Desarrollar tipologías de diseño y de este ejercicio generar pautas que den fundamento a las tendencias de diseño y producción en nuestro país cumpliendo los objetivos de esta investigación, de acuerdo a las demandas del medio y la innovación tecnológica disponible.

\section{PREEXISTENCIAS AMBIENTALES}

Los espacios arquitectónicos o urbanos interactúan con el ambiente, modificando, aprovechando o sufriendo las preexistencias ambientales. Esta interacción puede darse en múltiples escalas. Considerar las preexistencias es dejar de lado la arquitectura única, la exhibición personalista o desprecio insolidario que fragmenta la ciudad (Bohigas, cit. en Rogers, 1961).

Una adecuada calidad ambiental del hábitat construido se alcanza a partir de un conjunto de técnicas, infraestructuras y equipamientos que en conjunto definen el concepto de acondicionamiento ambiental (Maristany, 2015); adherimos con Hernández (2011) que destaca que la actual preocupación por el deterioro ambiental y por un entorno que sea eficiente en el uso de los recursos debe capitalizarse y apuntar a generar herramientas que permitan afrontar los retos que presenta la sostenibilidad desde un enfoque multidisciplinar, entendiendo hábitat no solo como el tejido residencial, sino involucrando la red de equipamientos y espacio público que lo integra al resto de la ciudad (Hernández Achury, 2011).

Trabajamos la situación real de las condicionantes del lugar con sus preexistencias como el agua, el clima, el paisaje y el ruido. El ruido está considerado como uno de los factores más contaminantes.

\section{DOMÓTICA E INMÓTICA}

Investigamos y diseñamos con la tecnología inmótica que nos permite lograr el confort, ahorro energético, la seguridad con la mayor economía. Además nos acerca al diseño inclusivo al que apuntamos.

En los años 70, con el objetivo principal de generar un ahorro en el consumo, surgen las primeras automatizaciones en edificios (Romero Morales et al, 2006). Luego de las primeras automatizaciones en el aire acondicionado, con el uso de los termostatos, se comenzaron a usar los sensores para los controles de humedad, caudal de aire, etc., en los sistemas de climatización, y para los controles de intrusos, en los sistemas de alarmas. 
Se la llamó domótica, que proviene de domus: casa y tica: de domotique (del francés): robótica (Enciclopedia Larousse, 1988). El término domótica tiene una génesis análoga a la del término informática, sustituyendo el prefijo que significa información por otro derivado de la palabra latina domus, que significa casa. También reciben un trato análogo en la bibliografía en lengua inglesa, en la que son más comunes otros términos como computing en lugar de informática o smart house e intelligent building en lugar de domótica (Recuero, Caminos, 1999).

Cuando se orienta a edificios terciarios, no viviendas, estamos ante la presencia de la inmótica", que realiza la gestión de la energía incluyendo las automatizaciones de las actividades y el trabajo (Morales, Serrano, Lozano, 2006). En este trabajo usaremos el término inmótica, que es la nominación específica para la domótica cuando la tipología no es vivienda y dejaremos el uso del término domótica para las generalidades.

\section{ESPACIOS RESIDUALES, INSTERSTICIOS ESPACIALES}

Reconocemos en la compleja trama urbana de las ciudades espacios públicos llamados residuales, que en realidad son "intersticios espaciales". Si pensamos a un intersticio como el espacio que media entre dos partes de distintos objetos o entre dos elementos del mismo cuerpo, podemos decir que un espacio intersticial es aquél de función y uso no definido, situados entre espacios que sí tienen una carga funcional y simbólica para los ciudadanos. Estos espacios no necesariamente son de dimensiones reducidas, ni deben tener una posición poco visible. Son simplemente espacios que, por el diseño y apropiación del sistema de espacios públicos de la ciudad, quedan relegados en el imaginario ciudadano, pasando desapercibidos a usuarios, tomadores de decisiones y planificadores.

\section{METODOLOGÍA}

La Metodología usada es empírica: se ensayan y verifican diferentes diseños en 3D, y con otros softwares de verificación que utilizan los asesores especialistas, (esta etapa se realizará durante el año 2019/2020).

Las etapas del proceso pueden resumirse en:

1. Elaborar un diagnóstico del estado actual del diseño y producción de microarquitectura domótica y sustentable, considerando los ejemplos más relevantes existentes locales y del mundo.

2. Trabajo en el sitio intersticial, relevando las relaciones con el ambiente.

3. Encuestas a usuarios de espacios urbanos públicos y semi públicos, en cuanto a usos, interacción, accesibilidad, etc.
4. Ensayos de proyectos con alternativas de sistemas y de usos.

5. Sistematización de la información.

6. Hipótesis de forma, uso, tecnología y sistemas.

7. Construcción de prototipos en modelos $3 \mathrm{D}$ y en maquetas virtuales.

8. Presentación del diseño al gobierno de la Municipalidad de Córdoba.

Intervinimos el espacio intersticial elegido en los alrededores de Plaza España, uno de los principales accesos al área central de la ciudad. El espacio, hoy vacante, es adyacente a una importante vía vehicular; tienen un gran flujo de peatones a lo largo del día y durante toda la semana, ya que conecta el área central con el Parque Sarmiento, (monumento nacional) y con la "media legua de oro", el principal circuito de museos provinciales y municipales de la ciudad. Se eligió ocuparlo sin interrumpir los espacios de circulación peatonal y vehicular, pero aprovechando la vegetación de gran porte existente.

Se trata de nuevas configuraciones que se trabajaron con la adaptación, o engrosamiento o completamiento de estos intersticios, con propuestas de nuevos usos a nivel urbano. Con estos dispositivos, se buscó aportar equipamiento urbano al espacio público. El equipamiento urbano es algo más que el mobiliario urbano, ya que contiene, y quizás no está ubicado en la acera, es sostenible cuando se integra con el paisaje y a la vez genera energía limpia a través de paneles solares y/o eólica. Se trata de integrar servicios para la vida urbana y para la naturaleza.

Finalmente, se tomaron en cuenta a los habitantes que serán usuarios de todas las edades, y con capacidades especiales, proyectando con inclusividad. Realizamos encuestas digitales.

\section{PROPUESTA}

Los elementos urbanos identifican la ciudad y a través de ellos podemos conocer y reconocer las ciudades. Realizamos nuestra propuesta de microarquitectura que es un espacio físico para el twitter \#quetenemos hoy, con atención personalizada y con autoconsulta, reforzando la difusión de las actividades de la Secretaría de Cultura, tanto en formato de imágenes digitales, como en formato de imágenes estáticas. Promovemos la participación de los usuarios, en la modificación del espacio (Imagen 4).

Las características de todo elemento de microarquitectura urbana son:

- Estética.

- Solidez y duración

- Funcionalidad 


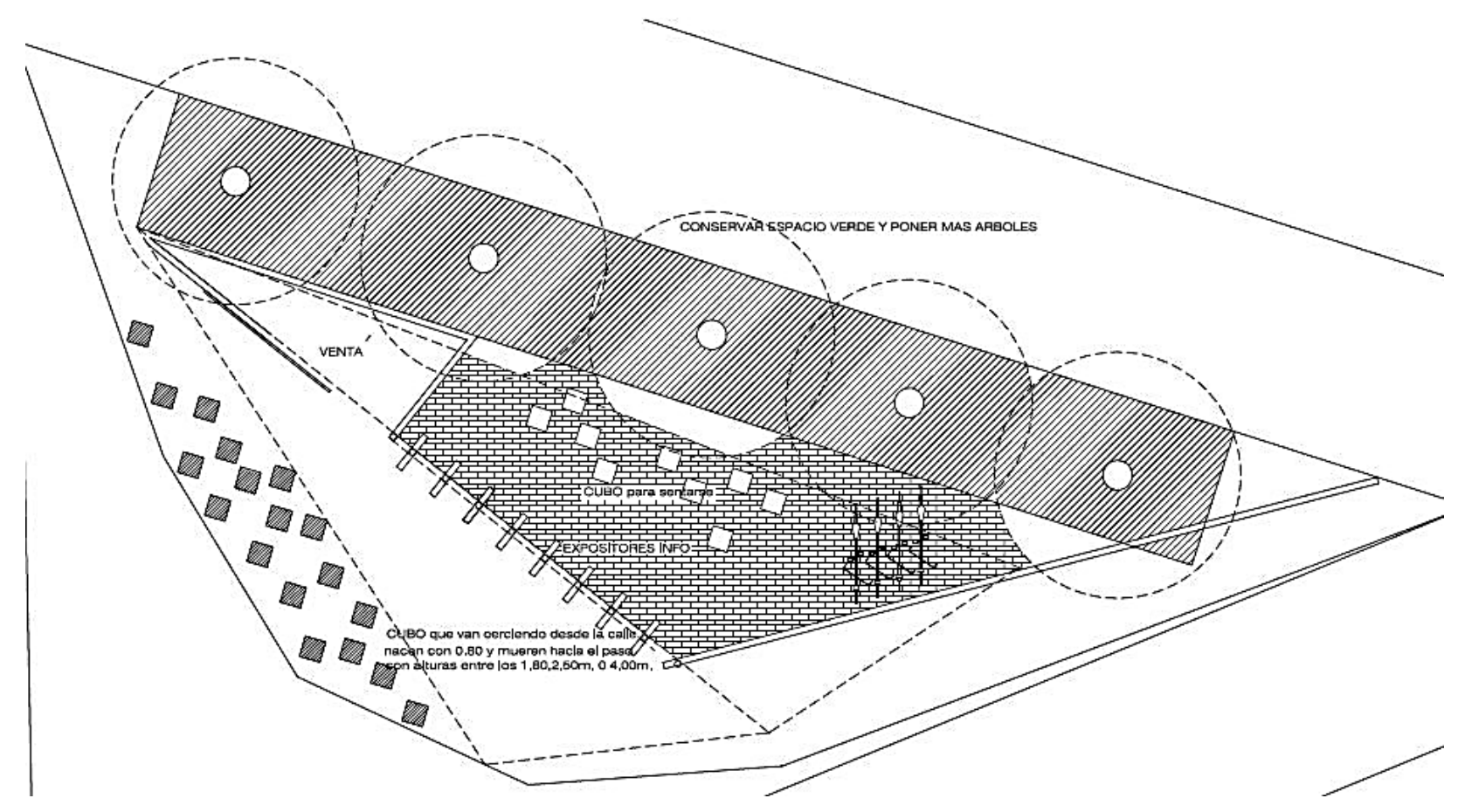

Imagen 5: planta general. Propia.

- Idoneidad de instalación.

- Facilidad de reparación.

- Facilidad de mantenimiento.

Además de respetar la ordenanza municipal debe

- Ofrecer al usuario ciudadano

- Protección y separación.

- Información o comunicación.

- Servicio, reposo y seguridad.

\section{INTERACCIÓN DEL USUARIO CON LOS OBJETOS Y \\ EL ESPACIO}

En esta misma línea se implementa el diseño con tecnología, incorporando la domótica tanto en los equipos como en las envolventes, conforme a los requerimientos funcionales, morfológicos, de sustentabilidad y técnicos

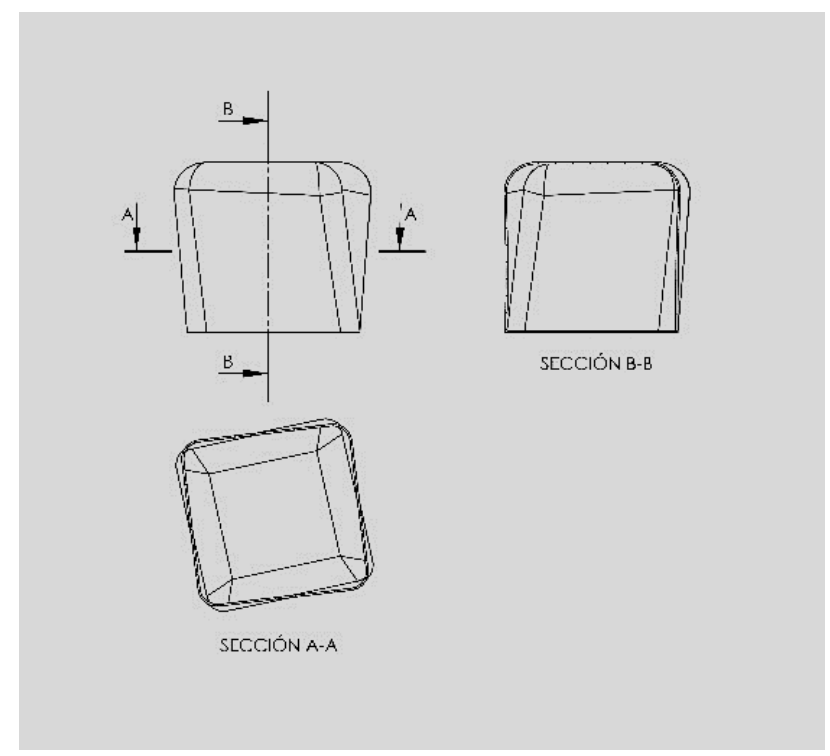

Imagen 6: equipos- bancos, imagen propia.
3Dropios, considerando las características socioeconómicas y constructivas del medio, ya que trabajamos en un proyecto construible.

Trabajar con la domótica- inmótica nos permite optimizar el manejo de los recursos y por lo tanto aumentar la eficiencia de los sistemas de aprovechamiento y control.

En cuanto a los usuarios y las posibilidades de interacción consideramos que proveer a los mismos de la posibilidad de tener control tanto de sus acciones, como de tener acceso a la información aumenta el confort y la satisfacción de las acciones de ese momento y de la relación con otros actores, usuarios, espacios. Proponemos pantallas con transmisión en vivo de los espectáculos actuales y con transmisión de espectáculos que pasaron. Los equipos de autoconsulta posibilitan la

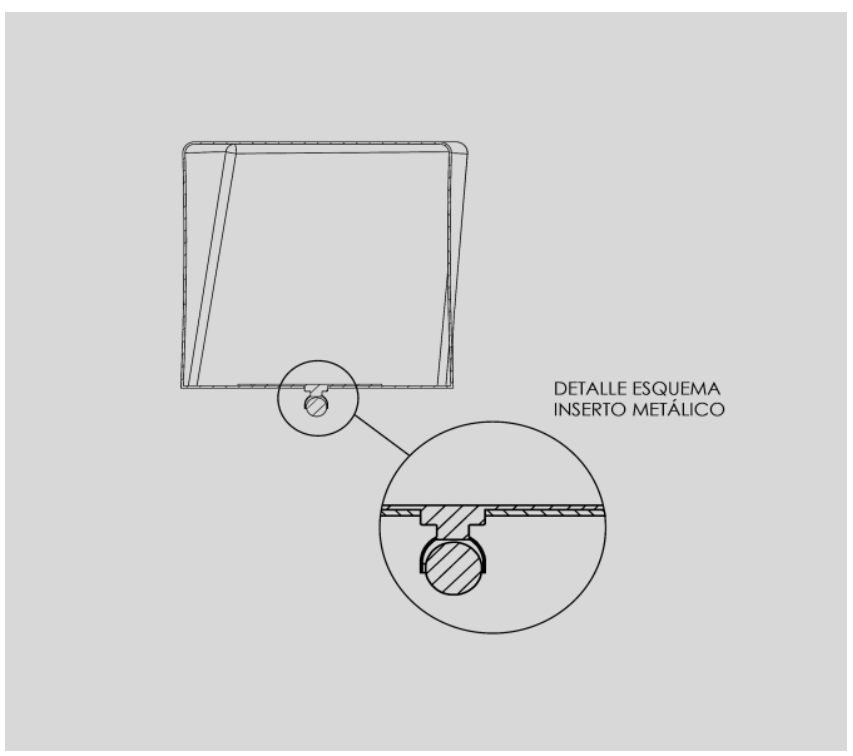

Imagen 8: rotomoldeado. inserto imagen propia. 
reserva de entradas y/o venta de las mismas, así como también la carga de tarjeta de colectivos -REDBUS- con tarjeta de débito. Los equipos de autoconsulta permiten a cada usuario consultar la grilla de espectáculos, así como sacar entradas, pagando con tarjeta. También se pueden conseguir los tickets de aquellos espectáculos que sean gratuitos. En estas acciones los usuarios pueden tener asistencia de alguna persona que orienta en el uso de las máquinas. Aquellos que no lo precisen lo resuelven solos, ya que los resultados de las encuestas realizadas muestran la necesidad de personal que asesora y ayuda con los equipos y con el hashtag.

El planteo espacial contempla la posibilidad de reunión, de muestras, de representación de espectáculos, etc, con la movilidad de los equipos de asientos y carteleras en forma inmótica (Imagen 5 y 6). Por lo tanto, para permitir reuniones y representaciones los bancos se mueven automáticamente a través de rieles.

En cuanto a la tecnología propuesta para los equipos, incluyendo tanto a los bancos como los equipos de autoconsulta, es plástico rotomoldeado, fundamentalmente porque es resistente a la intemperie y al uso intenso. El rotomoldeado nos da la posibilidad de incorporar Insertos metálicos, que permitan el funcionamiento del mecanismo de regulación de la posición de los bancos, dentro del mismo proceso de producción de la pieza, lo que asegura: resistencia de los vínculos y máxima eficiencia productiva.
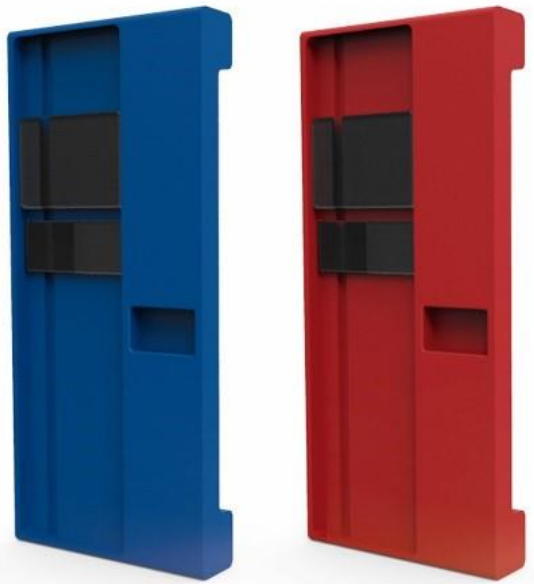

Imagen 9: Equipos de autoconsulta

Esta tecnología, de bajo costo productivo y de baja inversión inicial, además se adecúa a series bajas de producción, por lo que resulta funcional para una primera etapa de lanzamiento del proyecto. También nos da la posibilidad de producción con material reutilizado y resulta así sustentable. (Imagen 7 y 8 )

Con los prototipos en tres dimensiones y animados, y las verificaciones realizadas, estaremos en condiciones de extender esta propuesta a los organismos municipales.
Imagen 7: bancos rotomoldeados
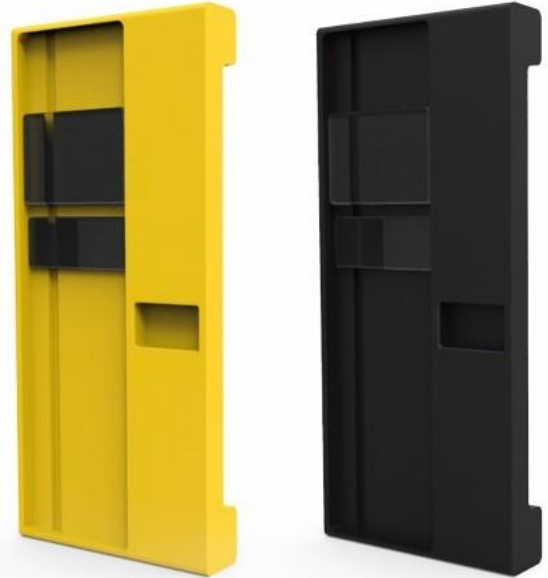

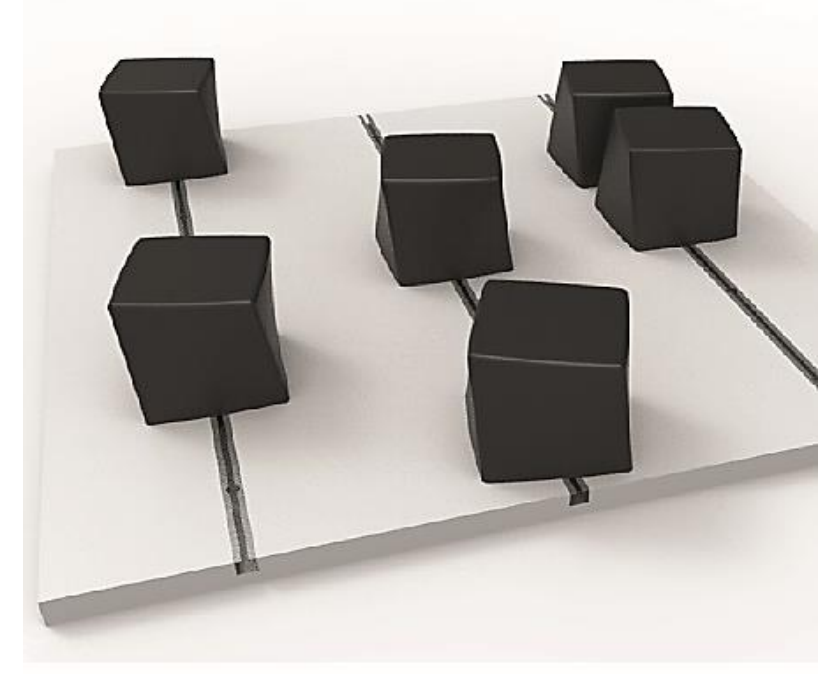

\section{RESULTADOS Y DISCUSIÓN}

El diseño de espacios que ocupen los intersticios urbanos, que responda y se adecue a su entorno, o se destaque, para los usos que la sociedad demanda es una tarea muy comprometida. Para ello es fundamental la comprensión del medio y una lectura clara detenida de su comportamiento y de los requerimientos de los usuarios.

Mejorar el medioambiente del espacio público, engrandecer con el diseño que conlleva orden y que

contempla la función, la morfología y lo sustentable, mediante propuestas concretas de modelos de uso urbanístico, arquitectural y de equipamiento urbano. Se trata de integrar servicios para la vida urbana y para la naturaleza.

Es un desafío para este grupo trabajar desde lo micro, equipamientos, a escala mayores y complejas como son los espacios de la ciudad. Se plantea con esta investigación el desafío de regenerar sectores, de considerar actividades y proyectar para ellas con tecnologías de vanguardia, en una sinergia sostenible e inclusiva. 
Con este proyecto hemos querido aceptar un cambio de actitud de la población urbana, ofreciendo posibles soluciones de mobiliario para el espacio urbano que facilitan el uso de las nuevas tecnologías móviles en espacios públicos y el uso de energías alternativas, como la solar, para satisfacer las necesidades de energía.

La domótica y la inmótica están cada vez más relacionadas con el concepto de sustentabilidad, por su potencial como herramientas tecnológicas destinadas no solo a aumentar la calidad de vida en los edificios sino también y principalmente por su utilidad como recurso técnico destinado a aumentar la eficiencia energética de los sistemas construidos, el ahorro energético y por su contribución a la sustentabilidad del hábitat construido. Además, el menor costo de puesta en funcionamiento y mantenimiento favorece su implementación en situaciones cada vez más diversas, llegando a cada vez más ciudadanos.

Mejorar el medioambiente del espacio público, es engrandecer con el diseño que conlleva orden y que contempla la función, la morfología y lo sustentable, mediante propuestas concretas de modelos de uso urbanístico y arquitectural y de equipamiento urbano. Se trata de integrar servicios para la vida urbana y para la naturaleza.

\section{BIBLIOGRAFÍA}

Alessi, C., (2014), Dopo gli anni Zero: il nuovo design italiano. Roma, Editori Laterza.
CEDOM, (2007), Asociación Española de Domótica. Cuaderno

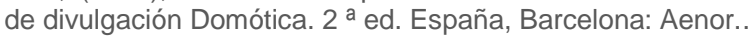

De Los Santos Arsanay, A., (2009), Diseño de interacción centrada en el usuario, Doctorado, Universidad de Vigo, España

Gutiérrez-Rubí, A, (2010), Tecnopolítica. El uso y la concepción de las nuevas herramientas tecnológicas para la comunicación, la organización y la acción política colectivas. España.

Gutierrez-Rubi, Antoni, Los hilos de Twitter, 13 mayo 2018 https://www.gutierrez-rubi.es/2018/05/13/los-hilos-de-twitter/, recuperado el 5 de junio 2018 ,

Loader y Mercea (Hrsg.), (2012): Social Media and Democracy. Innovations in Participatory Politics. London: Routledgehttp://www.grafiko.cat/

PORTAL del Gobierno de Córdoba, recuperado http://www2.cordoba.gov.ar/portal/ recuperado 19 de junio 2016

Twitter de la secretaría de cultura, recuperado https://twitter.com/hashtag/quetenemoshoy?src=hash, $19 \mathrm{de}$ junio 2016

Pérez de Lama, J,(2017), recuperado https://arquitecturacontable.wordpress.com/2017/06/10/aprox imacion-a-una-definicion-de-tecnopoliticas/

Pérez de Lama, J., (2015), Deleuze / Foucault y el poder: incitar, suscitar combinar... recuperado : https://arquitecturacontable.wordpress.com/2015/05/06/dele uze-foucault-y-el-poder-incitar-suscitar-combinar/

Recuero, A. (1999) Informes de la Construcción, Vol. 50

Rogers, E, (1955), Pre-existing Conditions and Issue of Contemporary Building Practice, editorial en Casabella 